\title{
Lack of a late asthmatic response after hypertonic saline challenge in children
}

\author{
W. Eder*, M. Schreuer**, J. Riedler*
}

Lack of a late asthmatic response after hypertonic saline challenge in children. W. Eder, M. Schreuer, J. Riedler. (C) ERS Journals Ltd 1999.

ABSTRACT: Hypertonic saline challenge has become a standardized method for measuring airway responsiveness. However, there is still uncertainty about the occurrence of a late asthmatic response. Therefore, the present study was designed to assess a possible late asthmatic response after hypertonic saline challenge in children.

Twenty-one children with mild to moderate bronchial hyperresponsiveness were studied. On days 1 and 2, forced expiratory volume in one second (FEV1) was measured hourly from 10:00 $\mathrm{h}$ to 22:00 $\mathrm{h}$ to assess diurnal variation of lung function. On the third study day, a hypertonic saline challenge was performed and FEV1 was measured as on control days. The possibility of a late asthmatic response was tested by comparing FEV1 levels up to $12 \mathrm{~h}$ after the challenge on the intervention day to FEV 1 levels on control days.

In no subjects were the FEV1 values following the challenge found to be considerably below the individual mean of the control days. Furthermore, a nonparametric approach was applied for each child and the population looked into as a whole. Again, no late asthmatic response was detectable.

The results of this study suggest that in children with mild to moderate bronchial hyperresponsiveness a late asthmatic response does not occur 4-12 h after a $4.5 \%$ saline challenge.

Eur Respir J 1999; 14: 1179-1184.

Hypertonic saline (HS) challenge has become a standardized method for measuring bronchial hyperresponsiveness (BHR) in epidemiological studies and for clinical purposes [1-3]. There is increasing evidence that the inhalation of a hypertonic aerosol creates a transient change in osmolarity of the airway surface fluid. Cell shrinkage and water loss from mucosa and submucosa seem to stimulate the production and release of endogenous substances from the epithelium and the mucosa $[4,5]$. These substances act on the smooth muscle leading to contraction, activate other cells and act on blood vessels, which leads to changes in permeability and induction of airway wall oedema [6]. Mast cells, epithelial cells and nerves appear to play a key role [7-10]. The endogenous mediators released during inhalation of HS could potentially initiate an enhancement of the underlying inflammation of the airways to an extent such as to cause a late asthmatic response (LAR) and an increase of the underlying nonspecific BHR. Exercise-challenge, cold air challenge and isocapnic hyperventilation seem to involve similar mechanisms as HS in producing an early asthmatic response (EAR) via changes in osmolarity. However, the precise pathway is still a matter of debate and there is still controversy about the existence of an LAR in these challenges. Several studies have described the occurrence of an LAR following nonallergen challenges [11-13] but more studies have been unable to document an LAR [1419].

To date, there is uncertainty about an LAR after inhalation of hypertonic aerosols [20] and no study has been
*Paediatric Pulmonology, Children's Hospital Salzburg, Austria **Statistical Consultant, Dept of Sociology, University of Salzburg, Austria

Correspondence: J. Riedler, Paediatric Pulmonology, Children's Hospital, Muellner Hauptstraße 48 A-5020 Salzburg, Austria. Fax: 4366244822604

\section{Keywords: children}

hypertonic saline challenge

late asthmatic response

Received: November 31998

Accepted after revision July 181999 carried out in children. Therefore, the present study was designed to assess a possible LAR after HS challenge in children using statistical methods suggested in recently published recommendations [21].

\section{Materials and methods}

\section{Subjects}

Twenty-five out of 75 children that had responded positively to a bronchial provocation test using $4.5 \%$ saline in an epidemiological study, which had been carried out 1 yr previously in Salzburg, Austria [3] agreed to be rechallenged and fulfilled the following inclusion criteria for taking part in the present study: a previous positive response to hypertonic saline challenge; an assessment of respiratory disease status by a paediatric respiratory physician; stable asthma with inhaled $\beta_{2}$-agonists on demand to control symptoms; baseline forced expiratory volume in one second (FEV1) $>65 \%$ of predicted value; no inhaled corticosteroids or cromolyn during the last 2 months; no chest infection in the preceding 4 weeks; and the ability to perform reproducible pulmonary function tests.

Informed written consent was obtained from each child and at least one parent, and the study was approved by the Hospital Ethics Committee for Human Studies.

The first step of the study was to instruct each child in self-measurement of FEV1 using a "hand held" spirometer (MicroLoop II; Micro Medical Ltd. Rochester, UK) with the aim of performing three consecutive FEV1 readings 
with a variability of $<5 \%$. The children were asked to avoid strenuous exercise during the study days which could imitate an LAR when carried out on the challenge day or mask an LAR when performed on a control day.

\section{Control days}

On days 1 and 2, children measured FEV1 at home hourly between 10:00 $\mathrm{h}$ and 22:00 h. Three measurements were obtained on each occasion with variability $<5 \%$, and recorded in a protocol. The highest FEV1 reading was chosen. Medication - if used - and respiratory symptoms were noted. These 2 days served as "control days" to assess diurnal changes in lung function for each child.

\section{Intervention day}

On day 3 , all children performed an HS challenge in the Respiratory Laboratory according to a previously published standardization [2]. In brief $4.5 \%$ saline was nebulized via a De Vilbiss Ultraneb 2000 (De Vilbiss, Somerset, PA, USA) connected to $65 \mathrm{~cm}$ of corrugated aerosol tubing and a two-way non-rebreathing valve (Cat No. 560200; with diverter, Cat. No. 850500; Laerdel, Stavanger, Norway). During the challenge, the nebulizer output was kept constant and the dose of saline increased successively by doubling the inhalation time starting with 0.5 then 1, 2, 4 and 8 min with subjects inhaling at tidal volumes. FEV1 was measured in duplicate $60 \mathrm{~s}$ after each challenge step. Lung function was measured with the same "hand held" spirometer as the child had used on control days. The challenge ended when the FEV1 had fallen by $\geq 15 \%$, or a cumulative inhalation time of 15.5 min had been achieved. The nebulizer canister plus tubing was weighed prior to the challenge and after the final step on an electronic balance to assess the total amount of aerosol nebulized and the nebulizer output. $\mathrm{min}^{-1}$. Individual dose-response curves were constructed by plotting the percentage fall in FEV1 from baseline on a linear scale against the cumulative dose of aerosol delivered on a logarithmic scale. The value of the provocative dose causing a 15\% fall in FEV1 (PD15) was obtained by linear interpolation of the last two inhalation steps.

Children with a positive response to HS challenge subsequently inhaled a $\beta$-agonist (400 mcg salbutamol via a spacer). Comparisons of FEV1 on the day of intervention with FEV1 on control days started $4 \mathrm{~h}$ after inhalation of salbutamol.

All challenges were performed between $08: 30 \mathrm{~h}$ and 10:00 $\mathrm{h}$ and FEV1 measurements at home were carried out from $10: 00 \mathrm{~h}$ to $22: 00 \mathrm{~h}$ as on control days.

\section{Statistical analysis}

Data entry and analysis were made using SPSS for Windows (Release 6.0; SPSS Inc., Chicago, IL, USA). The possibility of an LAR was tested by comparing FEV1 levels up to $12 \mathrm{~h}$ after HS challenge on intervention day to FEV1 levels on control days without any intervention.

The aim of the statistical analysis was to establish whether the FEV1 levels following the challenge fell considerably in comparison to the levels on normal days. This question was posed for each subject individually as well as for the population as a whole. On the individual level, both an analysis based on the normal distribution (repeated ttests with the significance level adjusted for multiple testing) as well as a nonparametric analysis (sign tests) were carried out. For the question generalized to the population as a whole, the sign test was carried out. (For further details see "Appendix".)

\section{Results}

Of the 25 children initially enrolled, 22 completed the three consecutive study days. One child withdrew from the study because of time commitments, another was unable to perform reproducible FEV1 measurements and one child had unstable asthma. Twenty-one of the 22 children responded positively to HS and were available for statistical analysis. A paediatric respiratory physician had diagnosed mild asthma in 18/21 children and asymptomatic BHR to $4.5 \%$ saline in $3 / 21$ children based on respiratory symptoms, physical examination and lung function tests. Twelve children showed mild (PD15; $>6 \mathrm{~mL}$ ), and 9 children moderate (PD15; 2.01-6 mL) BHR. Further characteristics of these 21 children including atopic status, baseline FEV1 $\%$ predicted, and PD15 values are presented in table 1.

No child reported any deterioration of symptoms up to $12 \mathrm{~h}$ after the challenge test. Erroneously, two children (Subjects 2 and 19) inhaled one puff of a bronchodilator at 14:00 $\mathrm{h}$ and 21:00 $\mathrm{h}$, respectively, on intervention day. Therefore valid comparisons are not available from 14:00 h-18:00 h in Child 2 and 22:00 h for Child 19.

Characteristics of the 21 subjects that responded positively to hypertonic saline challenge and performed forced expiratory volume in one second (FEV1) measurements on all three study days

\begin{tabular}{lccccr}
\hline Child & Sex & $\begin{array}{c}\text { Age } \\
\text { yrs }\end{array}$ & $\begin{array}{c}\text { Atopic } \\
\text { status }\end{array}$ & $\begin{array}{c}\text { Baseline FEV1 \% } \\
\text { predicted }\end{array}$ & PD15 \\
\hline 1 & M & 14 & Yes & 89 & 4.1 \\
2 & $\mathrm{~F}$ & 14 & Yes & 87 & 2.1 \\
3 & $\mathrm{M}$ & 14 & Yes & 93 & 26.0 \\
4 & $\mathrm{M}$ & 14 & Yes & 94 & 29.0 \\
5 & $\mathrm{M}$ & 14 & Yes & 92 & 42.5 \\
6 & $\mathrm{M}$ & 14 & Yes & 77 & 4.6 \\
7 & $\mathrm{M}$ & 15 & Yes & 75 & 5.4 \\
8 & $\mathrm{M}$ & 15 & Yes & 84 & 5.5 \\
9 & $\mathrm{M}$ & 15 & Yes & 83 & 4.8 \\
10 & $\mathrm{M}$ & 14 & Yes & 89 & 8.8 \\
11 & $\mathrm{~F}$ & 15 & Yes & 90 & 7.0 \\
12 & $\mathrm{M}$ & 15 & Yes & 94 & 25.7 \\
13 & $\mathrm{~F}$ & 15 & Yes & 92 & 5.4 \\
14 & $\mathrm{M}$ & 15 & ND & 91 & 22.3 \\
15 & $\mathrm{M}$ & 15 & Yes & 82 & 2.8 \\
16 & $\mathrm{M}$ & 15 & No & 72 & 14.2 \\
17 & $\mathrm{M}$ & 14 & ND & 92 & 7.2 \\
18 & $\mathrm{M}$ & 14 & Yes & 88 & 12.4 \\
19 & $\mathrm{M}$ & 15 & No & 101 & 23.1 \\
20 & $\mathrm{~F}$ & 15 & Yes & 75 & 3.9 \\
21 & $\mathrm{~F}$ & 15 & Yes & 96 & 8.0 \\
\hline
\end{tabular}

*: atopic status defined as a positive allergy test (radioallergosorbent test RAST) or skin-prick test; PD15: provocative dose of $4.5 \%$ saline that casues a $15 \%$ fall in FEV1 from baseline; M: male; F: female; ND: not done, because the child refused to undergo an allergy test. 

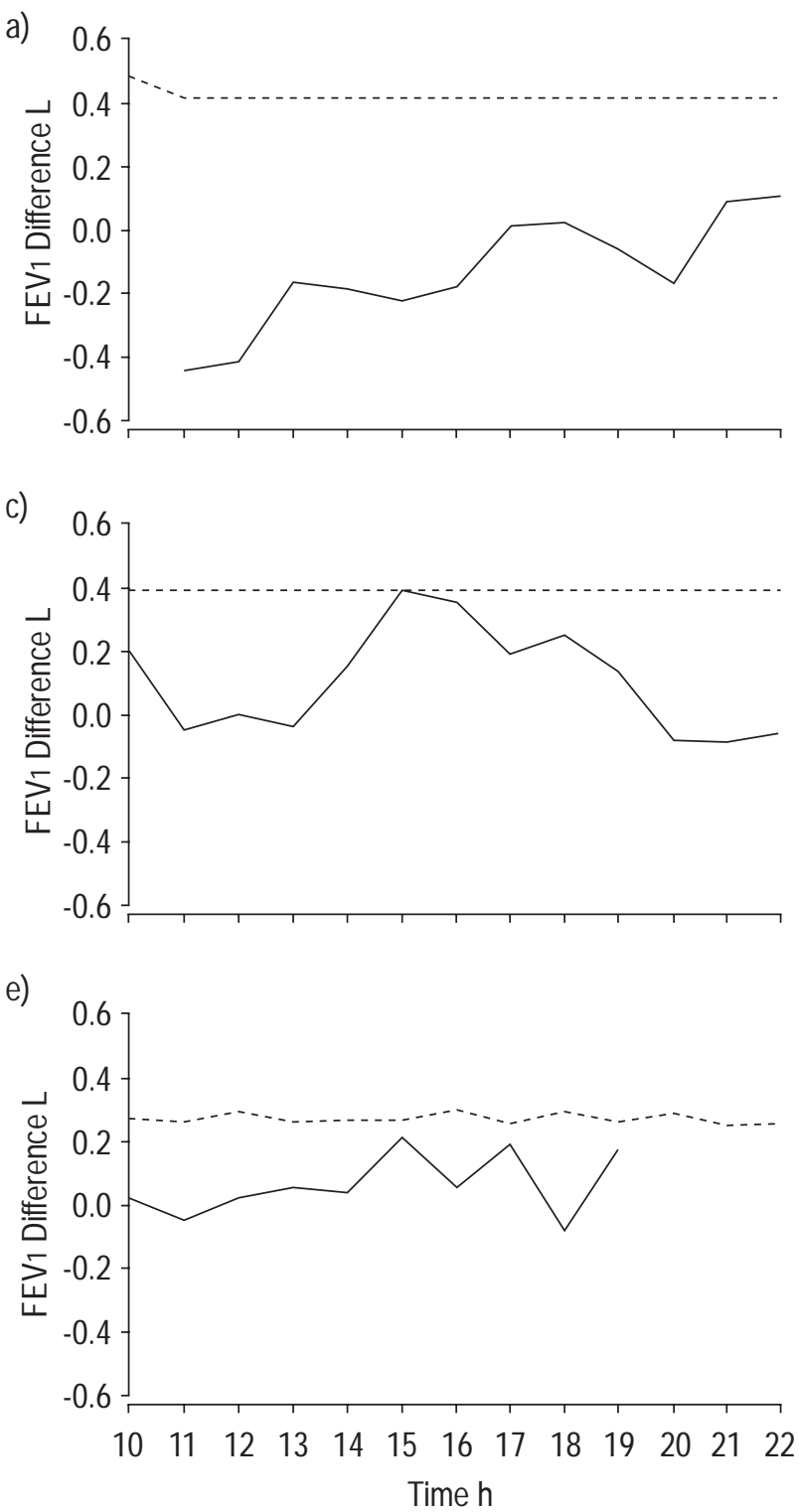

b)

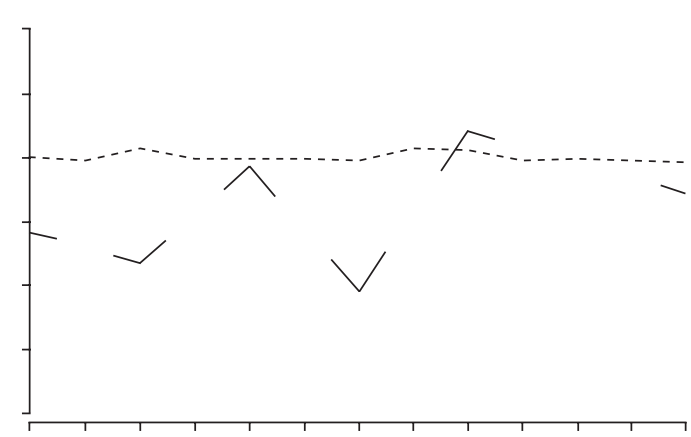

d)

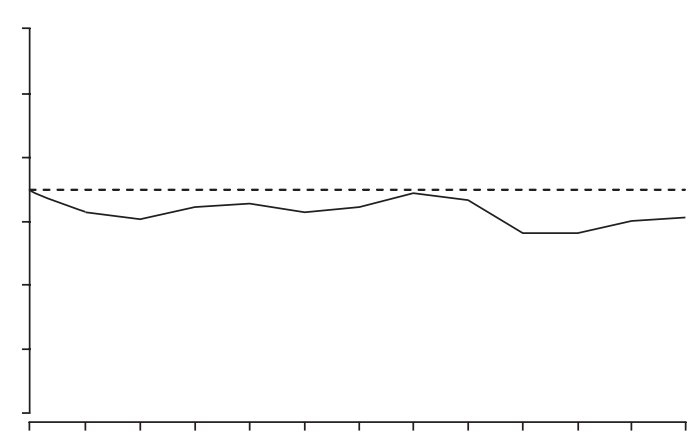

f)

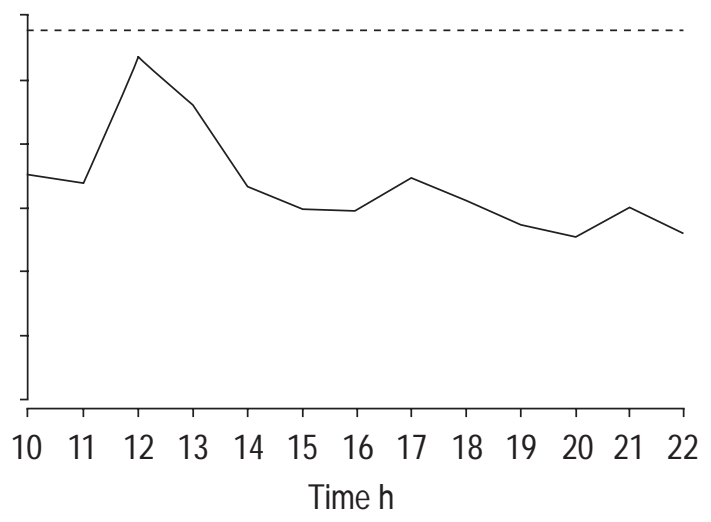

Fig. 1. - Difference in forced expiratory volume in one second (FEV1) against time for a) Child 1, b) Child 2, c) Child 8, d) Child 12, e) Child 14, f) Child 16. : the difference between the sample mean (Control-FEV1) and the sample intervention-FEV1 measurement; - - -: the critical value $(\alpha=5 \%)$ for this difference, determined by the t-test. A late asthmatic response is indicated if the lower line crosses the upper line at two consecutive time points. The broken lower line $(-)$ in $\mathrm{b}$ ) and the early end of the lower line $(-)$ in e) indicate missing values at these time points. Time is given in the 24 -h clock.

\section{t-tests}

No subject had two consecutive significant drops in FEV1 on intervention day and consequently no subject had an LAR. The results are best presented graphically and for 6 of the 21 subjects this is done in figure 1. The null hypothesis is rejected at some time point if the lower line (difference between the sample mean and the sample intervention-FEV1 measurement) crosses the upper line (critical value for this difference determined by the t-test). This happened for Child 8 at 15:00 h and for Child 2 at 18:00 h. The results for Child 2 are somewhat problematical since there are no two consecutive time points $1 \mathrm{~h}$ apart at which both an intervention measurement and at least one control measurement were made. The other 4 children whose line diagrams are shown in figure 1 include two subjects (Child 12 and Child 14) who dem- onstrated "almost" significant results in the sign-test (see below) and two subjects (Child 1 and Child 16) chosen randomly out of the remaining 17 who showed absolutely no evidence of any possible LAR.

SDs, degrees of freedom and number of valid comparisons for each child are presented in table 2 .

\section{Sign-tests}

Applying the sign-test to each of the 21 subjects individually shows a trend towards a significant result in two cases: Child 12 and Child $14(\mathrm{p}=0.0547$ and $\mathrm{p}=0.0625$ respectively, see table 1). For Child 12, who has the smallest estimated SD, the FEV1 measurement on the day of intervention is most consistently below the mean of the control measurements (fig. 1) although the drop is never 
Table 2. - sDs: degrees of freedom (df) and number of valid comparisons ( $T$ ) (t-test), and $p$-values of the sign-test for all 21 subjects

\begin{tabular}{|c|c|c|c|c|}
\hline \multirow[b]{2}{*}{ Child No. } & \multicolumn{3}{|c|}{ t-test } & \multirow{2}{*}{$\begin{array}{l}\mathrm{p} \text {-value of } \\
\text { the sign test }\end{array}$} \\
\hline & $\mathrm{s}$ & $\mathrm{df}$ & $\mathrm{T}$ & \\
\hline 1 & 0.111 & 12 & 10 & 0.828 \\
\hline 2 & 0.063 & 9 & 4 & 0.500 \\
\hline 3 & 0.071 & 8 & 7 & 0.773 \\
\hline 4 & 0.256 & 11 & 9 & 0.746 \\
\hline 5 & 0.031 & 13 & 10 & 0.828 \\
\hline 6 & 0.255 & 13 & 9 & 0.746 \\
\hline 7 & 0.095 & 9 & 7 & 1.000 \\
\hline 8 & 0.104 & 13 & 10 & 0.377 \\
\hline 9 & 0.076 & 13 & 9 & 0.910 \\
\hline 10 & 0.040 & 13 & 10 & 0.989 \\
\hline 11 & 0.050 & 8 & 6 & 0.109 \\
\hline 12 & 0.026 & 13 & 10 & 0.055 \\
\hline 13 & 0.140 & 11 & 5 & 0.813 \\
\hline 14 & 0.071 & 9 & 7 & 0.063 \\
\hline 15 & 0.065 & 11 & 7 & 0.773 \\
\hline 16 & 0.150 & 13 & 10 & 0.377 \\
\hline 17 & 0.087 & 11 & 10 & 1.000 \\
\hline 18 & 0.116 & 13 & 10 & 0.377 \\
\hline 19 & 0.198 & 12 & 12 & 0.387 \\
\hline 20 & 0.053 & 13 & 10 & 0.172 \\
\hline 21 & 0.075 & 11 & 7 & 0.992 \\
\hline
\end{tabular}

s: pooled SD.

more than $2.1 \%$. For Child 14 . the FEV1 on the day of intervention is also fairly consistently below the control measurements (fig. 1), with a maximum drop of $5.3 \%$.

In the population as a whole, of 180 comparisons 84 are pluses $(46.7 \%)$ giving a far from significant result $(\mathrm{p}=0.82)$ (see "Appendix", paragraph 2).

\section{Discussion}

The results of this study show no statistically significant and no clinically relevant fall in FEV1 within 4-12 h after an EAR to a HS challenge in children with mild to moderate BHR, indicating that there is lack of an LAR after HS challenge. To the best of the authors' knowledge, this is the first study looking into a possible LAR after HS in children.

Verifying the existence of an LAR poses methodological problems because there is still a lack of a definition of an LAR. It is commonly described as a secondary deterioration in lung function several hours after a bronchial provocation but the amount of this decrease is not standardized. Therefore, comparisons of lung function after the challenge to diurnal variation on a control day are suggested, instead of an arbitrary chosen decrease in lung function. This method reduces the risk of false positive results due to high diurnal variations and of a false negative result in the case of very low diurnal variation. In the statistical analysis the authors applied different methods. Following STENTON et al. [21], FEV1 measurements were compared on control and intervention days using the t-test for each child individually. This requires normally distributed values, an assumption which cannot be validated in small samples. Therefore, applying a nonparametric approach, the authors replaced the requirement of normal distributions and equal variances by the assumption that the
FEV1 values on control and challenge days were symmetrically distributed about their respective means. A further approach was to look into the population as a whole using the sign-test. With these three different statistical methods, the authors were unable to detect any LAR after HS challenge.

Bussieres et al. [20] described a possible LAR after HS challenge in 2 of 12 adult subjects. In one of the two subjects, Bussieres et al. [20] proposed high diurnal fluctuation of expiratory flows to be responsible for the late fall in FEV1 and possibly restriction from current medication might have contributed to some extent. The second subject with a significant difference between the maximal fall in FEV1 2-8 h after HS challenge and a control day also showed a high increase in methacholine responsiveness after HS challenge. It has been shown that the increase in nonspecific BHR to methacholine has a close relationship to the occurrence of an LAR after allergen challenge and the link between both is thought to be a complex inflammatory process in the airways [22-27]. However, there are some differences between the methods of Bussieres et al. [20] and the current study that may explain these findings. In their study, a fixed percentage of a fall in FEV1 within 2-8 h after an EAR was chosen to define an LAR and both subjects with a late fall in FEV1 inhaled $7.5 \%$ saline, in contrast to $4.5 \%$ saline in the present study. Besides a different statistical analysis, in the current study the FEV1 comparisons were performed from 4-12 $\mathrm{h}$ after the HS challenge with respect to the inhalation of $400 \mathrm{mcg}$ salbutamol immediately after the challenge. In the standardized protocol for the HS challenge in children, it is suggested to reverse the EAR by a $\beta$-agonist. This is particularly critical for field studies where children are not supervised for hours after the bronchial challenge as is the case in most laboratory studies. Theoretically, this medication could have influenced the course of an LAR and a secondary deterioration in lung function within $4 \mathrm{~h}$ after provocation would possibly not have been registered.

It also needs to be addressed that the current study population was fairly homogenous and did not include children with severe asthma or children with severe BHR to $4.5 \%$ saline. None of the children tested had used any antiinflammatory medications in the previous 2 months.

Self-measurernent of lung function could be criticised as being unreliable. However, in the present study each child was instructed individually by the same member of the study team in self-measuring lung function using the hand held spirometer. During the study an assessment of the technique of self-measurement of lung function was performed on the third study day. Only one child was not able to satisfy the criteria of correct self-measurement and was therefore excluded. The advantage of self-measurement was to avoid the need for an admission to hospital and to create conditions that reflect "real life".

Similar to HS challenge, hyperventilation during exercise seems to lead to hyperosmolarity in the airways [28]. Therefore, it is not unexpected that studies looking into a possible LAR after exercise challenges will be in line with the current results [14-18]. Delayed responses following recovery from EAR after exercise have been found in a minority of patients and have been suspected either to be not specifically related to the performance of exercise [14], to be a nonspecific epiphenomenon that is 
neither dependent upon the existence of an early response nor is unique to exercise [15], to be an artefact due to preexercise bronchodilation [16] or to be related to withdrawal from bronchodilator therapy [14]. Secondary deterioration in lung function after exercise was not reproducible on two occasions one week apart [17] and was also seen on control days [14-18].

Some common mechanisms of airway narrowing have been postulated for the bronchial response to cold air and distilled water. Comparisons with the response to distilled water are somewhat difficult to interpret due to differing methodology and statistical analysis $[11,12]$. In the only study looking into LAR after cold air challenge in children, VARGA et al. [19] found no LAR in 22 subjects as assessed by measurement of peak expiratory flow rate values.

In conclusion, the authors have shown the absence of a late asthmatic response 4-12 h after hypertonic saline challenge in children with mild to moderate bronchial hyperresponsiveness. These results further increase the safety of the bronchial provocation test with $4.5 \%$ saline, especially with regard to epidemiological studies in children.

\section{Appendix \\ Analysis based on the normal distribution (t-tests)}

Following Stenton et al. [21] the data was used to test the hypotheses by means of one sided t-tests:

$$
\begin{gathered}
\mathrm{H} 0 t: \mu_{\mathrm{i} t}(\text { Control })-\mu_{\mathrm{i} t}(\text { Intervention })=0 \\
\text { versus }
\end{gathered}
$$$$
\mathrm{H} 1 t: \mu_{\mathrm{i} t}(\text { Control })-\mu_{\mathrm{i} t} \text { (Intervention) }>0
$$

whereby $\mathrm{H} 0 t$ is the null hypothesis at time $t(t=10: 00 \mathrm{~h}$, $11: 00 \mathrm{~h}, \ldots 22: 00 \mathrm{~h}) ; \mathrm{H} 1 \mathrm{t}$ is the alternative hypothesis at time $t ; \mu \mathrm{i} t$ (Control) is the theoretical (population) mean of all possible measurements on control days for subject $i$ $(\mathrm{i}=1, \ldots, 21)$ at time $t$, and $\mu \mathrm{it}($ Intervention) is the theoretical (population) mean of all possible measurements on intervention days for subject $\mathrm{i}(\mathrm{i}=1, \ldots, 21)$ at time $t$ $(t=10: 00 \mathrm{~h}, 11: 00 \mathrm{~h}, \ldots ., 22: 00 \mathrm{~h})$.

Means, variances and SDS of the FEV1 measurements on control days were calculated for each subject at each time point where sufficient data was available. For each subject the sDs at different time points were pooled to give a single estimate of the SD which was assumed to remain constant over time. (This approach was taken after a repeated measures ANOVA on the SDS revealed that pooling over time was justified, pooling over subjects not.) For each subject, the pooled variance estimate was calculated by averaging the estimates calculated at the separate time points. The pooled SD is then the square root of this average variance and the number of degrees of freedom associated with this pooled SD equals the number of time-points at which two control measurements were made

The number of $t$-tests carried out for each subject $\left(\mathrm{T}_{\mathrm{i}}\right)$, equals the number of time points at which valid comparisons between control and intervention measurements can be made. A valid comparison can be made at time $t$ if at least one control measurement is available, an intervention measurement is available and no medication has been taken during the previous $4 \mathrm{~h}$. For each subject the significance levels for the $\mathrm{Ti}$ separate $t$-tests are adjusted for multiple testing so that for each subject an overall $5 \%$ significance level is maintained. A subject is said to have a late asthmatic response if there are two consecutive time points $\mathrm{t}$ and $\mathrm{t}-\mathrm{l}$ at which the null hypotheses $\mathrm{H} 0 t$ and $\mathrm{H} 0 t+1$ are rejected in favour of the alternative hypotheses $\mathrm{H} 1 t$ and $\mathrm{H} 1, t+1$.

\section{A nonparametric approach}

Replacing the assumptions of normal distributions with equal variances by the much weaker assumption that the control and intervention forced expiratory volume in one second measurements were symmetrically distributed about their respective means the authors tested:

$$
\begin{gathered}
\mathrm{H}_{0}: \mu \text { Intervention }=\mu \text { Control } \\
\text { versus } \\
\mathrm{H}_{1}: \mu \text { Intervention }<\mu \mathrm{Control}
\end{gathered}
$$

for each subject individually by the sign-test. Where, $\mathrm{H} 0$ is the null hypothesis; $\mathrm{H}_{1}$ is the alternative hypothesis; Intervention is the population mean of FEV1 levels on the intervention day; and $\mu$ Control is the population mean FEV1 on control days. The authors compared the measured mean FEV1 level on control days with the level on intervention days at all time points, recording a plus if the control level was higher, a minus if the control level was lower. Then the authors tested whether the probability of obtaining a positive comparison was equal to or higher than 0.5 . In order to answer the question whether in the population as a whole the mean FEV1 level following an intervention dropped below the mean "normal" level, the sign-test procedure was extended by accumulating the counts of plus and minus over all subjects.

\section{References}

1. Smith CM, Anderson SD. Inhalation challenge using hypertonic saline in asthmatic subjects: a comparison with responses to hyperpnoea, methacholine and water. Eur Respir J 1990; 3: 144-151.

2. Riedler J, Reade T, Dalton M, Holst D, Robertson CF. Hypertonic saline challenge in an epidemiologic survey of asthma in children. Am J Respir Crit Care Med 1994; 150: $1632-1639$.

3. Riedler J, Gamper A, Eder W, Oberfeld G. Prevalence of bronchial hyperresponsiveness to $4.5 \%$ saline and its relation to asthma and allergy symptoms in Austrian children. Eur Respir J 1998; 11: 355-360.

4. Gravelyn TR, Pan PM, Eschenbacher WL. Mediator release in an isolated segment in subjects with asthma. $\mathrm{Am}$ Rev Respir Dis 1988; 137: 641-646.

5. Belcher NG, Murdoch RD, Dalton N, et al. A comparison of mediator and catecholamine release between exerciseand hypertonic saline-induced asthma. Am Rev Respir Dis 1988; 137: 1026-1032.

6. Högman M, Almirall J, Mörk AC, et al. Nebulisation of hypertonic saline causes oedema ofthe airway wall. $J S u b$ microsc Cytol Pathol 1997; 29: 59-64.

7. Eggleston PA, Kagey-Sobotka A, Proud D, Adkinson NF, Lichtenstein LM. Disassociation of the release of histamine and arachidonic acid metabolites from osmotically activated basophils and human lung mast cells. Am Rev Respir Dis 1990; 141: 960-964. 
8. Finney MJB, Anderson SD, Black JL. Terfenadine modifies airway narrowing induced by the inhalation of nonisotonic aerosols in subjects with asthma. Am Rev Respir Dis 1990; 141: 1151-1157.

9. Anderson SD, du Toit J, Rodwell LT, Jenkins CR. Acute effect of sodium cromoglycate on airway narrowing induced by 4.5 percent saline aerosol. Chest 1994; 105: 673680 .

10. Makker HK, Holgate ST. The contributions of neurogenic reflexes to hypertonic saline-induced bronchoconstriction in asthma. J Allergy Clin Immunol 1993; 92: 82-88.

11. Foresi A, Mattoli S, Corbo GM, Verga AV, Sommaruga A, Ciappi G. Late bronchial response and increase in methacholine hyperresponsiveness after exercise and distilled water challenge in atopic subjects with asthma with dual asthmatic response to allergen inhalation. $J$ Allergy Clin Immunol 1986; 78: 1130-1139.

12. Mattoli S, Foresi A, Corbo GM, Valente S, Patalano F, Giappi G. Increase in bronchial responsiveness to methacholine and late asthmatic response after the inhalation of ultrasonically nebulized distilled water. Chest 1986; 90: 726-732.

13. Lee TK, Nagakura T, Papageorgiou N, Iikura Y, Kay AB Exercise-induced late asthmatic reactions with neutrophil chemotactic activity. N Engl J Med 1983; 308: 15021505.

14. Rubinstein I, Levison H, Slutsky AS, et al. Immediate and delayed bronchoconstriction after exercise in patients with asthma. N Engl J Med 1987; 317: 482-485.

15. Zawadski DK, Lenner KA, McFadden ER. Reexamination of the late asthmatic response to exercise. Am Rev Respir Dis 1988; 137: 837-841.

16. Karjalainen J. Exercise response in 404 young men with asthma: no evidence for a late asthmatic reaction. Thorax 1991; 46: 100-104.

17. Boner AL, Vallone G, Chiesa M, Spezia E, Fambri L, Sette L. Reproducibility of late phase pulmonary response to exercise and its relationship to bronchial hyperreactivity in children with chronic asthma. Pediatr Pulmonol 1992; 14: 156-159.

18. Hofstra WB, Sterk PJ, Neijens HJ, Kouwenberg JM, Mulder PGH, Duiverman EJ. Occurrence of a late response to exercise in asthmatic children: multiple regres- sion approach using time-matched baseline and histamine control days. Eur Respir $J$ 1996; 9: 1348-1355.

19. Varga EM, Eber E, Zach MS. Cold air challenge for measuring airway reactivity in children: lack of a late asthmatic reaction. Lung 1990; 168: 267-272.

20. Bussieres S, Turcotte H, Boulet LP. Hyperosmolarityinduced increases in airway responsiveness and late asthmatic responses. Eur Respir J 1991; 4: 290-295.

21. Stenton SC, Avery AJ, Walters EH, Hendrick DJ. Statistical approaches to the identification of late asthmatic response. Eur Respir J 1994; 7: 806-812.

22. Wenzel SE, Westcott JY, Larsen GL. Bronchoalveolar lavage fluid mediator levels 5 minutes after allergen challenge in atopic subjects with asthma: relationship to the development of late asthmatic responses. J Clin Immunol 1991; 87: 540-548.

23. Montefort S, Gratziou C, Goulding D, et al. Bronchial biopsy evidence for leukocyte infiltration and upregulation of leukocyte-endothelial cell adhesion molecules 6 hours after local allergen challenge of sensitized asthmatics airways. J Clin Invest 1994; 93: 1411-1421.

24. Jarjour NN, Calhoun WJ, Kelly EAB, Gleich GJ, Schwartz B, Busse WW. The immediate and late allergic response to segmental bronchopulmonary provocation in asthma. Am J Respir Crit Care Med 1997; 155: 15151521.

25. Shaver JR, Zangrilli JG, Cho SK, et al. Kinetics of the development and recovery of the lung from IgE-mediated inflammation. Am J Respir Crit Care Med 1997; 155: 442-448.

26. Cartier A, Thomson NC, Frith PA, Roberts R, Hargreave FE. Allergen-induced increase in bronchial responiveness to histamine: relationship to the late asthmatic response and change in airway caliber. $J$ Allergy Clin Immunol 1982; 70: 170-177.

27. Woolley KL, Adelroth E, Wooley MJ, Ellis R, Jordana M, O'Byrne PM. Effects of allergen challenge on eosinophils, eosinoplill cationic protein, and granulocyte macrophage colony-stimulating factor in mild asthma. Am J Respir Crit Care Med 1995; 151: 1915-1924.

28. Smith SM, Anderson SD. Hyperosmolarity as the stimulus to asthma induced by hyperventilation? J Allergy Clin Immunology 1986; 77: 729-736. 